\title{
Study on Rational Well Spacing Optimization of Low Permeability Gas Reservoir
}

\author{
Jian-guo Zhang, Yong Wu, Fang Ai \\ Nationl Engineering Laboratory for Low-permeability Oil/Gas Exploration and Development, Research Institute of Petroleum \\ Exploration and Development of Petrochina Changqing Oilfield Company, Shanxi Xian, China \\ Email: zhjg_cq@petrochina.com.cn,wuyong_cq@petrochina.com.cn, af_cq@petrochina.com.cn
}

Received 2012

\begin{abstract}
The Shanggu gas field is the low porosity and low permeability. Single well controlled reserves, economic limit well spacing and economic rational spacing through different methods are calculated. With the development experience of Su Lige gas field as guidance, the rational spacing of Shanggu gas reservoir is $700 \mathrm{~m} \times 900 \mathrm{~m}$ by calculating daily gas production rate and cumulative gas production with different well spacing using numerical simulation method.
\end{abstract}

Keywords: Low Permeability; Rational Well Spacing; Well Pattern Density; Reservoir Numerical Simulation

\section{Introduction}

With the enhancement of development technique of oil and gas field, many low permeability fields, which couldn't yield oil or gas economically in the past, are becoming more and more valuable[1]. We must demonstrate well spacing before or after the development of field [2-4]. Well spacing is of vital importance for ultimate recovery and economic benefit of oil and gas field, especially for low permeability gas reservoir, which is widely reported both at home and abroad[5-15]. Currently, there are two basic methods in papers, which research the rational well spacing of gas field, they are single well controlled reserves and numerical simulation. The well pattern density of low permeability area in Jingbian gas field is low and the control degree of production wells is also low, which are the main reasons why the degree of reserve recovery is low. In order to enhance the producing degree and recovery ratio, well spacing is needed to be changed. Based on the basic principal of well pattern density optimization, rational spacing is economic, should avoid well interference and meet the standard of maximum recovery ratio and producing degree. How can we calculate the rational spacing, which means maximum economic benefit and recovery ration can be achieved with minimum wells? This paper calculates the rational spacing, which is suitable to
Shanggu low permeability gas field, and recommends a rational spacing arrangement.

1) Relationship between Well Spacing And Sand Scale

The main factors affecting the rational spacing are single sand body scale, superposed features of sand body, pattern of composite sand body and sand body's control action of porosity and permeability.

From the results of geologic research, we know that channel width is $60-250 \mathrm{~m}$ and channel belt width is $600-2000 \mathrm{~m}$. According to channel belt width, horizontal spacing is $600-1500 \mathrm{~m}$. For the same sand body, well spacing is less than channel width (Table 1).

\section{Methods of Determining Well Spacing}

\subsection{Single Well Controlled Reserves}

Assuming that gas well controlled reserves is known, the sands are uniform throughout the controlled extent of the reservoir, and drainage area is cylinder radial flow area, according to parameters and evaluation result of developed Shanggu gas field, the single well controlled area can be written as

$$
A_{k}=\frac{100 N_{k} B_{g}}{p_{o r} h s_{g}}
$$

Table 1. Developmental Scale of Neopaleozoic Channel in Gaoqiao.

\begin{tabular}{cccccccccc}
\hline \multirow{2}{*}{ Zone } & \multicolumn{2}{c}{ Thickness of sand body $(\mathbf{m})$} & \multicolumn{2}{c}{ Channel width $(\mathbf{m})$} & \multicolumn{3}{c}{ Channel belt width (m) } \\
\cline { 2 - 9 } & Min & Max & Variation change & Min & Max & Variation change & Min & Max & Variation change \\
\hline $\mathrm{H}_{8 \mathrm{u}}$ & 0.78 & 9 & $4-6$ & 8.66 & 374.3 & $80-200$ & 38.3 & 3126.54 & $750-1600$ \\
$\mathrm{H}_{81}$ & 1 & 12.2 & $5-7$ & 12.7 & 597.98 & $150-250$ & 59.9 & 5405.98 & $1000-2000$ \\
$\mathrm{~S}_{1}$ & 0.58 & 8.06 & $3-5$ & 5.49 & 315.82 & $60-150$ & 22.47 & 2563.48 & $600-1200$ \\
$\mathrm{~S}_{2}$ & 0.54 & 8.7 & $4-5$ & 4.92 & 355.26 & $70-180$ & 19.76 & 2941.45 & $700-1500$ \\
\hline
\end{tabular}


where

$\mathrm{A}_{\mathrm{k}}$-single well controlled area, $\mathrm{Km}^{2} ; \mathrm{N}_{\mathrm{k}}$-geologic reserve controlled by single well, $10^{8} \mathrm{~m}^{3} ; \mathrm{B}_{\mathrm{g}}$-gas volume factor, dimensionless; h-Thickness controlled by single well, m; $\mathrm{s}_{\mathrm{g}}$-skin factor, dimensionless.

Single well controlled area is about $0.45 \mathrm{Km}^{2}$ by using this method to evaluate 43 gas wells. The well spacing is $0.67 \mathrm{Km}$ calculated by square area.

\subsection{Economic Limit Spacing}

Economic limit spacing is the minimum spacing in terms of economic benefit. Economic limit spacing is in direct correlation with economic limit reserve. Under the condition of without considering the risk of drilling and considering the cost of drilling engineering and surface construction, the operation cost of gas production, the selling price of gas and the loan interest rate, etc, the equation of production well spacing using economic limit spacing method can be written as

Gross input of certain pattern density:

$$
C_{i n}=A \cdot S\left(I_{D}+I_{F}+I_{B}\right)(1+R)^{\left(T_{1}+T_{2}+T_{3}\right) / 2}
$$

Gross output of this pattern density:

$$
C_{\text {out }}=10 \cdot N \cdot E_{R} \cdot C\left(P_{g}-O-T_{a x}\right)
$$

Gross profit:

$$
G=C_{\text {in }}-C_{\text {out }}
$$

When gross profit equals to zero, the pattern density is limit pattern density:

$$
G=C_{\text {in }}-C_{\text {out }}=0
$$

Then, economic limit pattern density $\mathrm{S}$ is

$$
\begin{gathered}
S=\frac{10 \cdot N \cdot E_{R} \cdot C\left(P_{g}-O-T_{a x}\right)}{A\left(I_{D}+I_{F}+I_{B}\right)(1+R)^{\left(T_{1}+T_{2}\right) / 2}} \\
L_{\min }=\sqrt{\frac{1}{S}}
\end{gathered}
$$

According to the development experience of Jingbian gas field, we know that when average reserves abundance is larger than $1.1 \times 108 \mathrm{~m} 3 \mathrm{~d} / \mathrm{km} 2$, the economic limit spacing is smaller than $0.700 \mathrm{~km}$.

Where

S-economic limit pattern density, wells/Km2; ID-drilling cost of single well(includes perforation, test, logging and so on), 104 yuan/well; IF-fracturing cost of single well, $10^{4}$ yuan/well; $\mathrm{I}_{B}$-surface construction cost of single well(includes system engineering, field construction, etc), $10^{4}$ yuan/well; $\mathrm{P}_{\mathrm{g}}$-selling price of gas, yuan $/ 10^{3} \mathrm{~m}^{3}$; C-commodity rate of gas, ratio; Ooperation cost of gas, yuan $/ 10^{3} \mathrm{~m}^{3}$; Tax-toll of gas, yuan $/ 10^{3} \mathrm{~m}^{3}$; A-gas bearing area, $\mathrm{km}^{2}$; R-yearly loan interest rate, ratio; $\mathrm{N}$-gas in place, $10^{8} \mathrm{~m}^{3} ; \mathrm{E}_{\mathrm{R}}$-recovery ratio with pattern density being $\mathrm{S}$, ratio; $\mathrm{C}_{\mathrm{m}}$-gross input, $10^{4}$ yuan; $\mathrm{C}_{\text {out }}$-gross output, $10^{4}$ yuan; G-gross profit, $10^{4}$ yuan; $\mathrm{T}_{1}$-years of stable production, year; $\mathrm{T}_{2}$-decreasing years with decline fraction being $20 \%$, year; $\mathrm{L}_{\text {min }}$-economic limit spacing, $\mathrm{km}$.

\subsection{Rational Spacing}

Economic limit spacing is rational pattern density with certain profit. If considering the profit is 0.2 times of selling price, then

$$
S=\frac{10 \cdot N \cdot E_{R} \cdot C\left(P_{g}-O-T_{a x}-0.2 P_{g}\right)}{A\left(I_{D}+I_{F}+I_{B}\right)(1+R)^{\left(T_{1}+T_{2}\right) / 2}}
$$

Superimposed with Shanggu reserves, we know that average reserves abundance is larger than $1.1 \times 10^{8} \mathrm{~m}^{3} \mathrm{~d} / \mathrm{km}^{2}$. The economic limit spacing is smaller than $0.834 \mathrm{~km}$.

\section{Rational Spacing Determined by Numerical Simulation}

On the basis of geologic model, we found mechanism model of Shan 135 well and G61-11 well. Basic parameters of mechanism model are length and width: $5000 \times 6000 \mathrm{~m}$, grid spacing: $100 \times$ $100 \mathrm{~m}$, reserves abundance: $1 \times 10^{8} \mathrm{~m}^{3} / \mathrm{km}^{2}$, five zones in vertical, which corresponds to subzone, namely, $\mathrm{H}_{8}, \mathrm{~S}_{1}, \mathrm{~S}_{2}$, Benxi, without considering Xiagu reservoir.

We consider 8 combinations of well spacing/horizontal range, as shown in Table 2. Results are listed in Figure 2, Figure 3 and Table 3. When individual well producing rate is $1 \times 10^{4} \mathrm{~m}^{3} / \mathrm{d}$ and comparing calculation results of different well spacing and horizontal range, we conclude that the shorter the well spacing is, the more the well number is and the higher the gas production rate is, the shorter the years of stable production is. When well spacing/horizontal range is $700 \times 900 \mathrm{~m}$, years of stable production is 3 years and both the gas production rate and recovery ratio is relatively high.

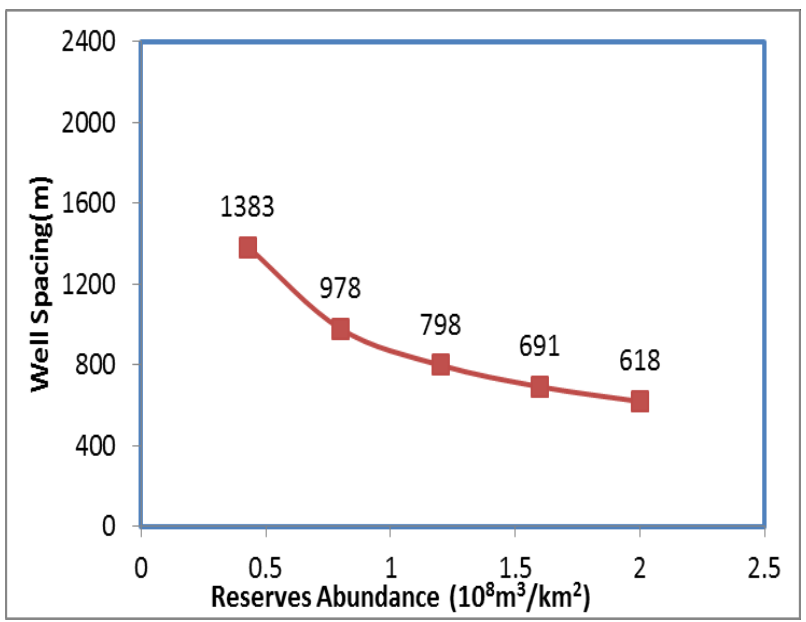

Figure 1. Relationship Graph between Economic Rational Spacing and Reserves Abundance of Ancient Gas Field.

Table 2. Design Table with Well Spacing/Horizontal Range.

\begin{tabular}{cccccccc}
\hline Well Spacing (m) & 1100 & 1000 & 900 & 800 & 700 & 600 & 600 \\
\hline Horizontal Range $(\mathbf{m})$ & 1300 & 1200 & 1100 & 1000 & 900 & 800 & 750 \\
\hline
\end{tabular}


Table 3. Statistical List of Optimum Spacing and Horizontal Range of Ancient Gas Field.

\begin{tabular}{|c|c|c|c|c|c|c|c|}
\hline Project No. & 1 & 2 & 3 & 4 & 5 & 6 & 7 \\
\hline Well Spacing (m) & 1100 & 1000 & 900 & 800 & 700 & 600 & 600 \\
\hline Horizontal Range (m) & 1300 & 1200 & 1100 & 1000 & 900 & 800 & 750 \\
\hline Number of wells（well） & 20 & 25 & 30 & 36 & 50 & 56 & 64 \\
\hline Daily Gas Production $\left(10^{4} \mathrm{~m}^{3} / \mathrm{d}\right)$ & 20 & 25 & 30 & 36 & 50 & 56 & 64 \\
\hline Gas Production Rate（\%) & 2 & 2.6 & 3.1 & 3.7 & 5.1 & 5.7 & 6.5 \\
\hline Cumulative Production at the end of Stable Production $\left(10^{8} \mathrm{~m}^{3}\right)$ & 5.41 & 5.53 & 5.64 & 5.82 & 5.94 & 6.10 & 6.34 \\
\hline Degree of Reserve Recovery at the end of Stable Production (\%) & 16.72 & 17.08 & 17.44 & 17.99 & 18.36 & 18.85 & 19.58 \\
\hline Cumulative Production after 20 Years $\left(10^{8} \mathrm{~m}^{3}\right)$ & 10.86 & 11.35 & 12.09 & 13.04 & 14.18 & 14.56 & 14.97 \\
\hline Degree of Reserve Recovery after 20 Years（\%) & 33.55 & 35.08 & 37.37 & 40.30 & 43.83 & 44.98 & 46.25 \\
\hline
\end{tabular}

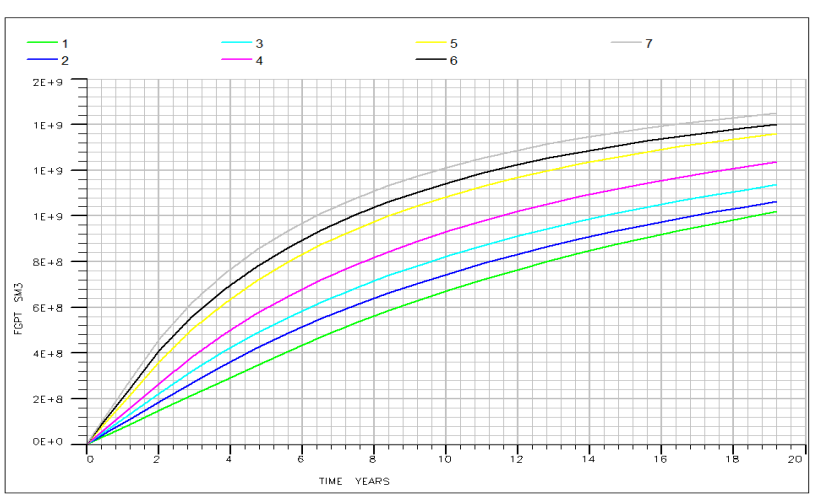

Figure 2. Cumulative Production Comparison Graph with Different Spacing and Horizontal Range.

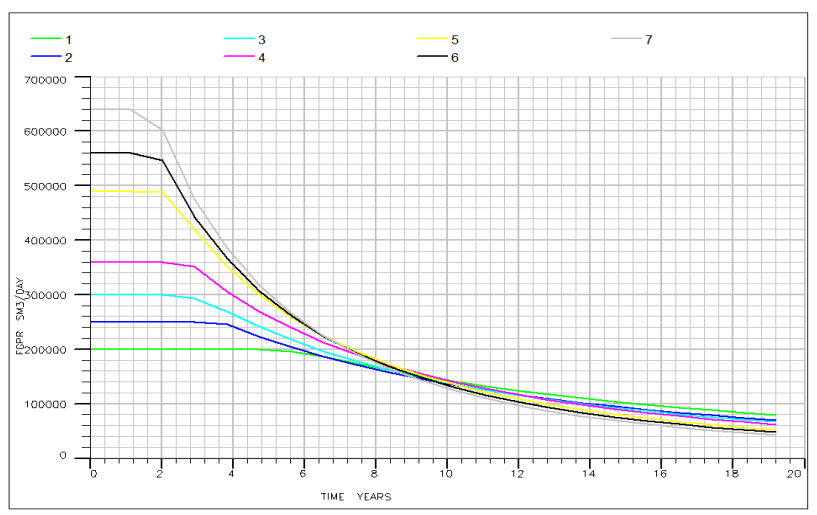

Figure 3. Daily Gas Production Comparison Graph with Different Spacing and Horizontal Range.

\section{Determination of Rational Spacing In Shang Gu Gas Reservoir}

Reserves abundance of Su Lige gas field is $1.2 \times 10^{8} \mathrm{~m}^{3} / \mathrm{km}^{2}$ and rational spacing and horizontal range is $600 \mathrm{~m} \times 800 \mathrm{~m}$. Reserves abundances of project area which is larger than $0.5 \times 10^{8} \mathrm{~m}^{3} / \mathrm{km}^{2}$ are $2612.07 \mathrm{~km}^{2}$, which accounts for $60 \%$ of total area. Average reserves abundance is $1.16 \times 10^{8} \mathrm{~m} 3 / \mathrm{km}^{2}$ and geologic reserve is $3030 \times 10^{8} \mathrm{~m}^{3}$, which accounts for $79.77 \%$ of Shanggu gas reserve, whose reserves is $3798.62 \times 10^{8} \mathrm{~m}^{3}$. So rational spacing and horizontal range of project area is larger than $600 \mathrm{~m} \times 800 \mathrm{~m}$.

Shanggu Gas reserves abundance of project area which is larger than $0.5 \times 10^{8} \mathrm{~m}^{3} / \mathrm{km}^{2}$ accounts for $79.77 \%$ of gas reserve. So the rational spacing and horizontal range is $700 \mathrm{~m} \times 900 \mathrm{~m}$.

\section{Conclusions}

1) Rational pattern density not only meets the requirement of development of gas field but should ensure maximum economic benefit. Rational pattern density is determined by geologic characteristic of gas field.

2) This paper determines the rational spacing of low permeability area in ancient gas field is $700 \mathrm{~m} \times 900 \mathrm{~m}$ by using economic limit spacing, economic rational spacing and numerical simulation. And this paper demonstrates an effective way of determining rational spacing and spacing arrangement of low permeability gas reservoir.

\section{REFERENCES}

[1] Wang Minghua, Gas Engineering [M] Beijing: Petroleum Industry Press, 1997.

[2] Chen Yuanqian, Reservoir engineering calculations [M] Beijing: Petroleum Industry Press, 1997.

[3] Li Shilun, Natural Gas Engineering [M],” Beijing: Petroleum Industry Press, 2000.

[4] Huang Bingguang, Practical And Dynamic Analysis Of Reservoir Engineering [M]," Beijing: Petroleum Industry Press, 1998.

[5] Wang Zhouhua, Guo Ping, Huang Quanhua,et al, "Studying The Pilot Production Pattern Well Spacing In The Da Niudi Lower Permeability Gas Field [J]," Journal of Southwest Petroleum Institute,2004, 26(4): 18-20.

[6] E. Quint, M. Singh, P. Huckabee, D. Brown, C.B. Brake, J. Bickley, B. Johnston, “4D Pressure Pilot To Steer Well Spacing 
in Tight Gas,” 2006, SPE 102745-MS

[7] Tang Yulin, Tang Guangping, "A Discussing On The Reasonable Well-Pattern Spacing Of Carboniferous Reservoirs In East Sichuan [J] Natural Gas Industry, 2000, 2(5): 57-60.

[8] Wang Guoyong, Liu Tianyu, Shi Juntai, Pattern well spacing optimization and analysis of factors affecting development effect in Sulige Gas Field [J] ,” Special Oil \& Gas Reservoirs, 2008, 15(5): 76-79.

[9] R. Recham, D. Bencherif, "Investigation of Optimum Well Spacing Based on a Combined Simulation and Economic Models,” Petroleum Society of Canada, 2003, Paper 2003-014

[10] V. Dehdari, B.Aminshahidy, A.Tabatabaei-nejad, "Well Spacing and Recovery Optimization of One of Iranian Oil Fields by Using Streamline and Reservoir Simulation,” 2008 SPE
112985-MS.

[11] Zhu Bin, Xiong Yanli, Wang Hao, "A Method To Determine A Reasonable Well Spacing In Low-Permeability Areas Of Carboniferous Gas Reservoirs,Eastern Sichuan Basin [J],” Natural Gas Exploration and Development, 2009, 32(4): 27-28.

[12] Zhang Bo, Li Jun, Lai Haitao, "su lige infiltrates the gas field pattern well spacing computational method discussion [J]," Petrochemical Industry Application, 2010, 29(6): 42-44 .

[13] Li Shuang, Zhu Xinjia, Jin Hui, Jing Yuanshuai, "Study on rational well pattern and well spacing in low permeability gas field [J],” Special Oil \& Gas Reservoirs, 2010, 17(5): 73-76.

[14] Dongbo He, Ailin Jia, Chengye Jia, et al,. "Well Spacing Optimization for Tight Sandstone Gas Reservoir,” 2010, SPE 131862-MS. 